\title{
Influence of capping groups on the synthesis of $\gamma-\mathrm{Fe}_{2} \mathrm{O}_{3}$ nanocrystals
}

\author{
Ming Yin \\ Department of Applied Physics and Applied Mathematics, Columbia University, \\ New York, New York 10027 \\ Amanda Willis \\ Department of Chemistry, Columbia University, New York, New York 10027 \\ Franz Redl \\ Department of Applied Physics and Applied Mathematics, Columbia University, \\ New York, New York 10027 \\ Nicholas J. Turro \\ Department of Chemistry, Columbia University, New York, New York 10027 \\ Stephen P. O'Brien ${ }^{\text {a) }}$ \\ Department of Applied Physics and Applied Mathematics, Columbia University, \\ New York, New York 10027
}

(Received 6 October 2003; accepted 7 January 2004)

\begin{abstract}
Monodisperse and uniform $\gamma-\mathrm{Fe}_{2} \mathrm{O}_{3}$ (maghemite) nanocrystals of variable size were prepared by thermal decomposition of iron pentacarbonyl $\left[\mathrm{Fe}(\mathrm{CO})_{5}\right]$ in the presence of surfactants, following controlled oxidation with trimethylamine $\mathrm{N}$-oxide as a mild oxidant. The influence of carboxylic acids with variable alkyl carbon chain lengths on the synthesis of $\gamma-\mathrm{Fe}_{2} \mathrm{O}_{3}$ nanocrystals was investigated. The effect of the molar ratios of surfactant to iron precursor was also studied. The nanocrystals were characterized by x-ray diffraction (XRD) and transmission electron microscopy (TEM). XRD showed the particles were highly crystalline at the nanometer scale. The results showed that the size and shape of the nanocrystal is strongly influenced by the decomposition temperature of iron pentacarbonyl and closely related to the length of carbon chain of the capping groups and the molar ratio of surfactant to iron precursor. Following controlled evaporation from nonpolar solvents, self-assembly into two-dimensional arrays could be observed by TEM. It was also found that the distance between the nanocrystals in self-assembled structures matched the length of the capping molecules very well.
\end{abstract}

\section{INTRODUCTION}

Magnetic nanocrystals have been attracting interest due to their unique properties and potential applications. ${ }^{1-7}$ Iron oxide nanocrystals in the magnetic form of maghemite have also been used as the precursor catalyst for chemical vapor deposition growth of carbon nanotubes, and it is generally believed that the diameter of the tubes is determined by the size of catalyst particles. ${ }^{2,3}$ Various chemical syntheses have been used to fabricate magnetic nanocrystals, ${ }^{5-8}$ among which, $\gamma-\mathrm{Fe}_{2} \mathrm{O}_{3}$ nanocrystals were synthesized by thermal decomposition of iron pentacarbonyl in the presence of surfactants (also referred to here as ligands), ${ }^{7}$ which bind to the surface of the nanocrystals and give rise to a steric barrier to aggregation. This method has widely been used because of

\footnotetext{
${ }^{a}$ Address all correspondence to this author. e-mail: so188@columbia.edu DOI: $10.1557 / J M R .2004 .0157$
}

the ease and reproducibility of the synthesis, as well as the uniformity, high crystallinity, and monodispersity of the product. Because the magnetic and catalytic properties of the nanocrystals are size-dependent, significant efforts have been concentrated on the precise control of particle size distribution. The capping group plays an important role in controlling the particle size. Previous studies used oleic acid, lauric acid, and octanoic acid and different metal-precursor-surfactant ratios $^{3,9}$ to prepare iron or iron oxide nanocrystals of varying sizes. It was also found that the size of PbSe nanocrystals could be controlled by the reaction temperature. ${ }^{10}$ However, absolute control over iron oxide nanocrystals still remains a challenge, and there is much to be gained from the ability to synthesize monodisperse nanocrystals of iron oxides with control over particle size. Here, we report the ability to control the size and size distribution of $\gamma-\mathrm{Fe}_{2} \mathrm{O}_{3}$ nanocrystals, based on choice of ligand, ligand:precursor ratio, and decomposition temperature. 


\section{EXPERIMENTAL}

\section{A. Materials}

Iron pentacarbonyl, trioctylamine, oleic acid $(90 \%$ tech.), elaidic acid, lauric acid, and butyric acid were from Aldrich and used as received. Dehydrated trimethylamine $N$-oxide was prepared by azeotropic distillation of trimethylamine $\mathrm{N}$-oxide dihydrate with toluene, both purchased from Aldrich.

\section{B. Synthesis of nanocrystals}

To prepare $\gamma-\mathrm{Fe}_{2} \mathrm{O}_{3}$ monodisperse nanocrystals, $4 \mathrm{mmol}$ of $\mathrm{Fe}(\mathrm{CO})_{5}$ and surfactant were added to $14 \mathrm{ml}$ trioctylamine and heated under nitrogen atmosphere. During the process, the initial yellowish color of the solution gradually changed to black upon the formation of $\mathrm{Fe}$ nanocrystals. The temperature of the color-change was maintained for $1 \mathrm{~h}$. The resulting black solution was cooled to room temperature, and $9 \mathrm{mmol}$ dehydrated $\left(\mathrm{CH}_{3}\right)_{3} \mathrm{NO}$ was added. The mixture was heated to $130{ }^{\circ} \mathrm{C}$ for $2 \mathrm{~h}$ (first stage) and then $350{ }^{\circ} \mathrm{C}$ (second stage) for $1 \mathrm{~h}$. After cooling to room temperature, the particles were precipitated with and washed with ethanol. The resulting $\gamma-\mathrm{Fe}_{2} \mathrm{O}_{3}$ nanocrystals can be easily redispersed in hexane.

\section{The influence of heating rate on the size of $\mathrm{Fe}_{2} \mathrm{O}_{3}$ nanocrystals}

A threefold excess of oleic acid was used as the surfactant. Heating rates were varied from $5{ }^{\circ} \mathrm{C} / \mathrm{min}$, $15^{\circ} \mathrm{C} / \mathrm{min}, 25^{\circ} \mathrm{C} / \mathrm{min}$, to $35^{\circ} \mathrm{C} / \mathrm{min}$.

\section{The influence of capping groups on nanocrystals}

Butyric acid, octanoic acid, lauric acid, and oleic acid were used as surfactants. The molar ratio between surfactant and iron precursor is 3:1. Iron pentacarbonyl and the carboxylic acid were heated under a nitrogen flow. During the process, the original yellowish color gradually changed to black. As soon as the black color was observed, the temperature was set constant and kept for $1 \mathrm{~h}$ until the reaction was complete. trans-oleic acid and cis-oleic acid were also used as surfactants separately. Both reactions were carried out at $350^{\circ} \mathrm{C}$ for $1 \mathrm{~h}$. Finally, the influence of molar ratio of surfactant to iron precursor was tested by using oleic acid as the surfactant; molar ratios were varied from $1: 1,2: 1$, to $3: 1$.

\section{E. TEM and XRD characterization}

$\gamma-\mathrm{Fe}_{2} \mathrm{O}_{3}$ nanocrystals were characterized using transmission electron microscopy (Jeol CX100) with an accelerating voltage of $100 \mathrm{kV}$ and $\mathrm{x}$-ray powder diffraction (Scintag $\mathrm{X}_{2} \mathrm{X}$-ray diffractometer). TEM samples were prepared by placing a drop of a dilute hexane dispersion of nanocrystals on the surface of a 400-mesh copper grid backed with Formvar and was dried in a vacuum chamber for $1 \mathrm{~h}$. X-ray diffraction (XRD) samples were prepared by drying a dispersion of nanocrystals on a piece of $\mathrm{Si}(100)$ wafer.

\section{RESULTS AND DISCUSSION}

\section{A. The influence of heating rate on the size of $\mathrm{Fe}_{2} \mathrm{O}_{3}$ nanocrystals}

To study the influence of capping groups on the synthesis of iron oxide nanocrystals, it is critical to eliminate other factors affecting the synthesis. It is assumed that the heating rate is one of them. ${ }^{11}$ Oleic acid, the most widely used surfactant in iron oxide nanocrystal synthesis, was used in this experiment. Under the prerequisite that all other experimental parameters were maintained constant, the heating rate showed influence on the size distribution of the particles. Figure 1 shows the particles prepared at different heating rates and isolated without further size selection. Although the average particle size is $10.0 \pm 1.2 \mathrm{~nm}$, the size distribution changed from $12 \%$ at $5{ }^{\circ} \mathrm{C} / \mathrm{min}$ (a) to $3 \%$ at $35{ }^{\circ} \mathrm{C} / \mathrm{min}$ (d) as can be seen from the pictures. As Fig.1 shows, particles are increasingly uniform and monodisperse with increasing heating rate. The XRD spectrum (Fig. 2) exhibited the highly crystalline peaks that can be matched well with the series of Bragg reflections corresponding to maghemite structure of $\mathrm{Fe}_{2} \mathrm{O}_{3}(a=8.350 \AA)$. Heating rate was fixed at $35{ }^{\circ} \mathrm{C} / \mathrm{min}$ in the following experiments because of the good result. The uniformity of the iron oxide nanocrystal is controlled by nucleation during the heating process. Generally speaking, a homogenous nucleation is dominant when the heating rate is relatively high, and therefore the nucleation is finished within a short time interval. The following homogeneous growth situation yields uniform particles. However, an inhomogenous nucleation process is more likely when the heating rate is low. In this case, particles are more likely to grow unevenly, and the size distribution will be broader.

\section{B. The influence of capping groups on nanocrystals}

The effectiveness of a capping group in the synthesis can be evaluated by the size, shape, size distribution, and crystallinity of the resulting particles. ${ }^{12-15}$ Generally speaking, smaller and more uniform nanocrystals indicate that the capping group interacts more strongly with the nanocrystals forming a more stable protective layer. Lower synthesis temperature indicates smaller size and higher crystallinity. ${ }^{16}$ Long-chain carboxylic acids are widely used in transition metal nanocrystal synthesis because they can adsorb onto the surface of the metal 


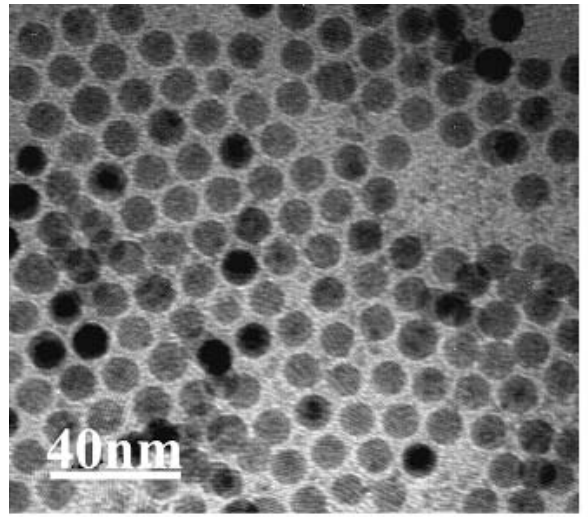

(a)

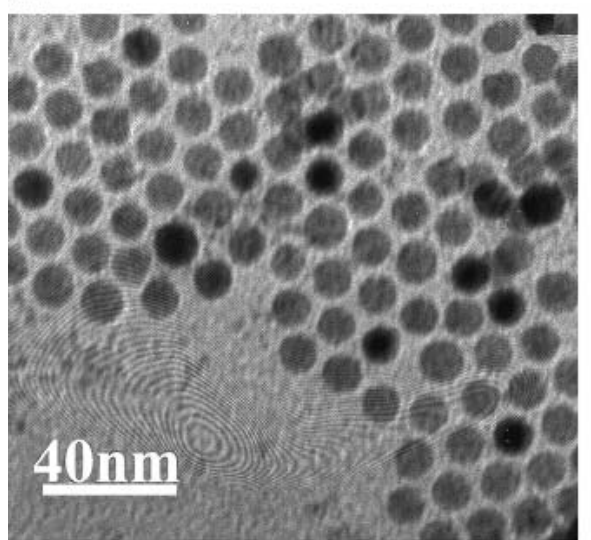

(c)

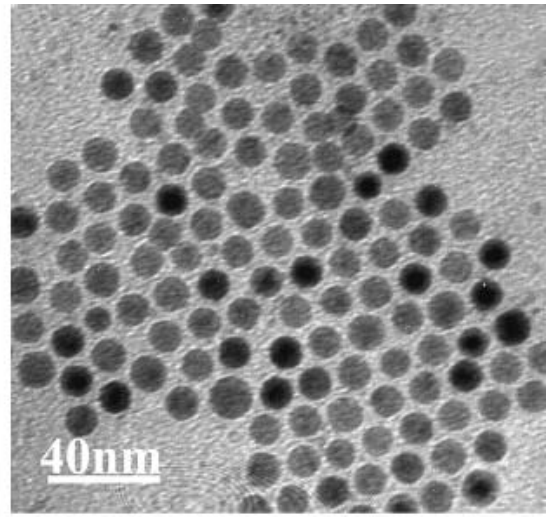

(b)

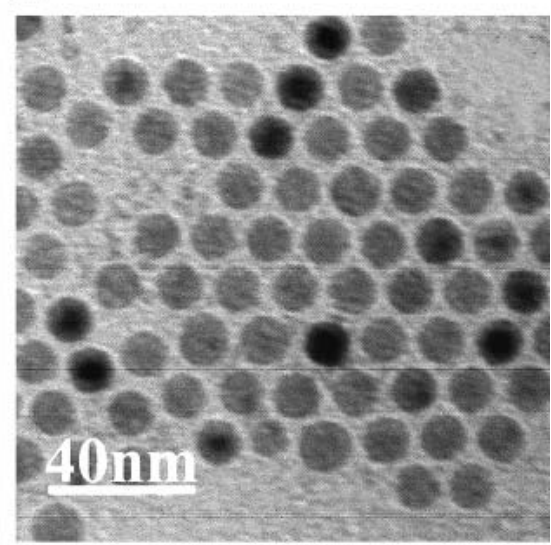

(d)

FIG. 1. Transmission electron micrographs of $\gamma-\mathrm{Fe}_{2} \mathrm{O}_{3}$ nanocrystals prepared with various heating rates: (a) $5{ }^{\circ} \mathrm{C} / \mathrm{min}$, (b) $15{ }^{\circ} \mathrm{C} / \mathrm{min}$, (c) $25^{\circ} \mathrm{C} / \mathrm{min}$, and (d) $35^{\circ} \mathrm{C} / \mathrm{min}$.

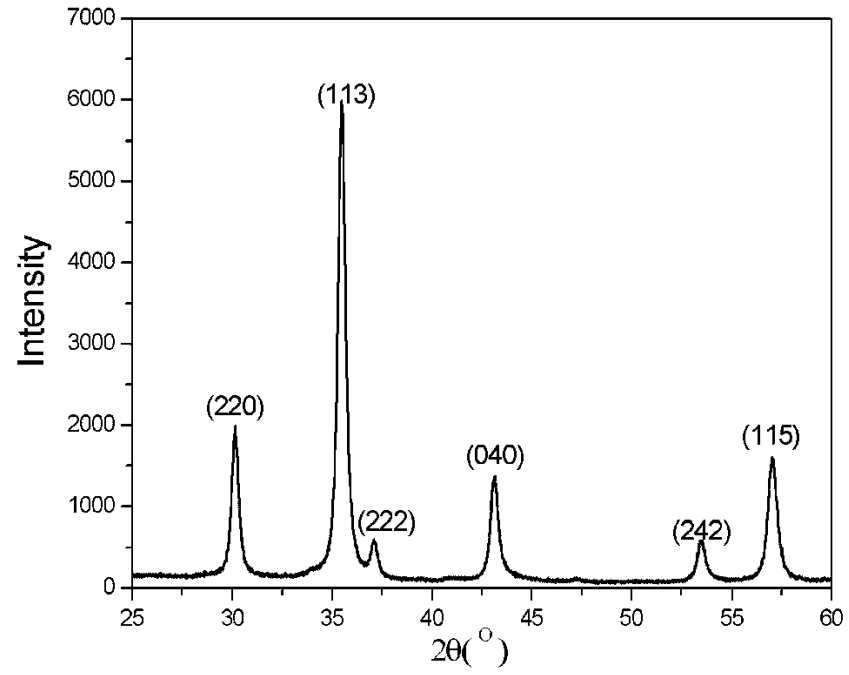

FIG. 2. X-ray powder diffraction patterns of $\gamma-\mathrm{Fe}_{2} \mathrm{O}_{3}$ maghemite nanocrystals.

forming a dense monolayer. ${ }^{2,3}$ Although oleic acid is the most widely used surfactant in iron oxide nanocrystal synthesis based on the decomposition of iron pentacar- bonyl because of the uniformity and monodispersity of the product, the connection between the role of the acid in the decomposition mechanism and the influence as capping group have not yet been clarified. In particular, one of the interesting topics to study is the structure of the carbon chain. Therefore, octanoic acid (C8), lauric acid (C12), and oleic acid (C18) were investigated, as shown in Table I. Experiments showed that the decomposition temperature increases as the length of the carbonchain increases as shown in Figs. 3(a,b), 3(c,d), and $3(\mathrm{e}, \mathrm{f})$. However, if no surfactant was used in the reaction, the actual decomposition temperature of iron pentacarbonyl was very high, around $360{ }^{\circ} \mathrm{C}$, which is much higher than the decomposition temperature with the existing of carboxylic acid as a surfactant. ${ }^{4}$ Obviously, the surfactant not only introduces a steric barrier for aggregation, but it also plays an active role during the reaction butyric acid (C8) decreases the decomposition temperature to $205{ }^{\circ} \mathrm{C}$. As the length of carbon-chain increases, the catalysis of carboxylic acid gradually becomes more insignificant as the dipole moment gets weaker and weaker. The dipole moment of oleic acid, with 18 carbon atoms, is smaller than other short-chain carboxylic acids. Working as a mild catalyst and effective steric barrier, 

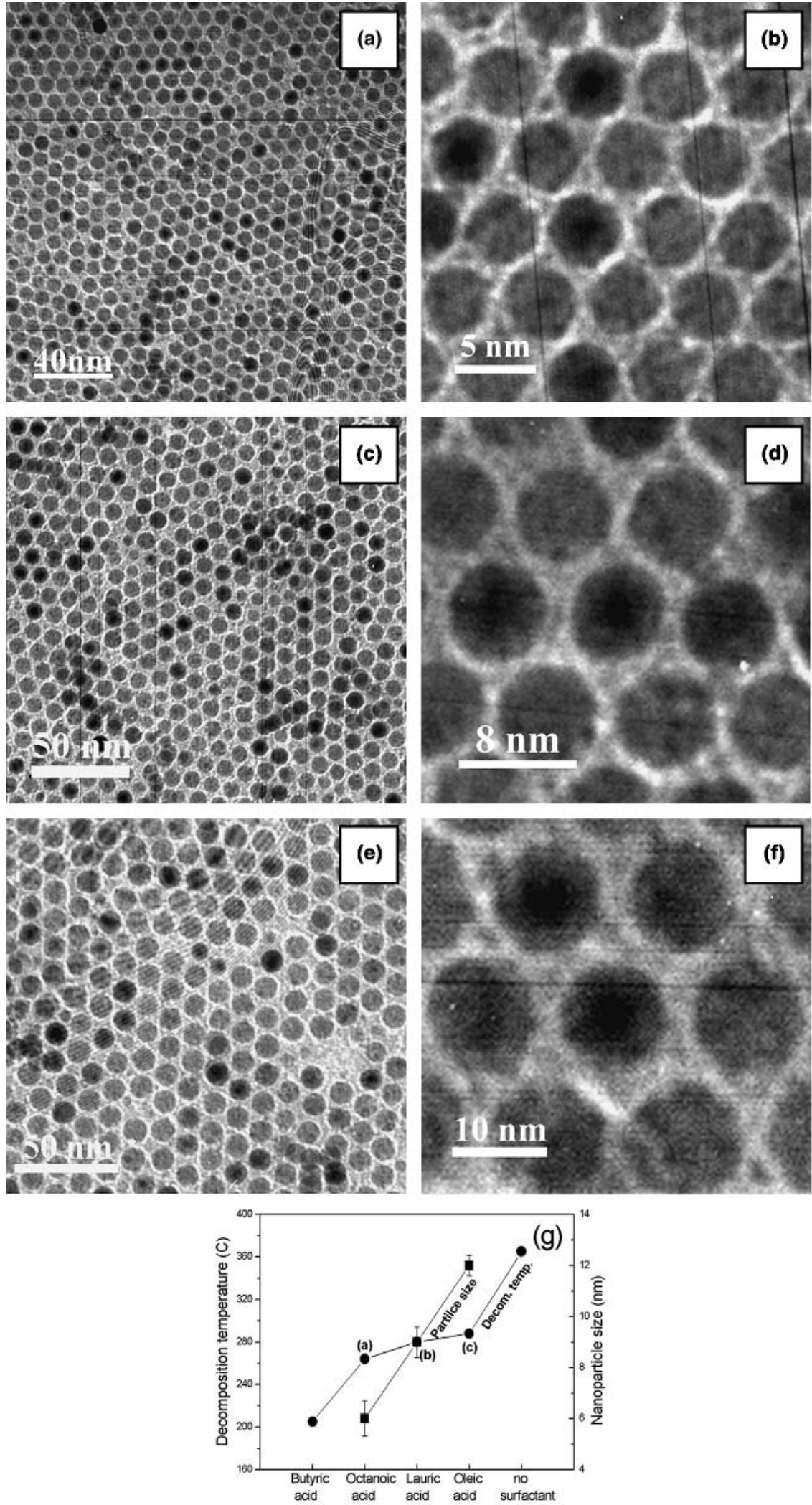

FIG. 3. TEM micrographs of $\gamma-\mathrm{Fe}_{2} \mathrm{O}_{3}$ nanocrystals coated with (a,b) octanoic acid, (c,d) lauric acid, and (e,f) oleic acid. (g) Decomposition temperature of iron pentacarbonyl with different capping groups. 
TABLE I. Structure and molecule length of carboxylic acid and influence on $\gamma-\mathrm{Fe}_{2} \mathrm{O}_{3}$ nanocrystal size.

\begin{tabular}{|c|c|c|c|c|c|c|}
\hline Surfactant & $\begin{array}{l}\text { Length of } \\
\text { carbon chain }\end{array}$ & Structure & $\begin{array}{l}\text { Molecule } \\
\text { length }^{\mathrm{a}}\end{array}$ & $\begin{array}{l}\text { Particle } \\
\text { size }\end{array}$ & $\begin{array}{c}\text { Inter-superlattice } \\
\text { distance }\end{array}$ & $\begin{array}{c}\text { Decomposition } \\
\text { temperature }\end{array}$ \\
\hline Butyric acid & $\mathrm{C} 4$ & & & None & & \\
\hline Octanoic acid & $\mathrm{C} 8$ & & $10.93 \mathrm{~A}$ & $6 \mathrm{~nm}$ & $2 \mathrm{~nm}$ & $264^{\circ} \mathrm{C}$ \\
\hline Lauric acid & $\mathrm{C} 12$ & & $17.8 \mathrm{~A}$ & $9 \mathrm{~nm}$ & $3.5 \mathrm{~nm}$ & $280^{\circ} \mathrm{C}$ \\
\hline Oleic acid & $\mathrm{C} 18$ & & $22.98 \mathrm{~A}$ & $12 \mathrm{~nm}$ & $4.5 \mathrm{~nm}$ & $288^{\circ} \mathrm{C}$ \\
\hline
\end{tabular}

${ }^{\mathrm{a}}$ Calculated by Chem3D with molecular mechanics using MM2.

oleic acid is widely used in iron nanocrystal synthesis and in many other syntheses of nanoparticles.

It was interesting to find that the presence of the carboxylic acid not only influences the decomposition temperature, but also has an effect on the size of the particles. Experiments show that particles are very big $(20 \mathrm{~nm})$ when no surfactant or a short-chain surfactant, butyric acid, was used with a comparable high dipole moment. Particles are uniform and monodisperse with sizes from $6 \mathrm{~nm}$ [Fig. 3(a,b)], $9 \mathrm{~nm}$ [Fig. 3(c,d)], and $12 \mathrm{~nm}$ [Fig. 3(e,f)] when octanoic acid, lauric acid, or oleic acid was used. The most regular particle shape was obtained when oleic acid was used as surfactant. The distances between particles in two-dimensional closest packed superlattices were $2 \mathrm{~nm}$ [Fig. 3(a,b)], $3.5 \mathrm{~nm}$ [Fig. 3 (c,d)], and $4.5 \mathrm{~nm}$ [Fig. 3 (e,f)] when octanoic acid, lauric acid, and oleic acid were used, which is about twice the length of the extended molecule length of the fatty acid molecules, as shown in Table I. In those two-dimensional superstructures, the surfactants are possibly not interdigitating as known from many other three-dimensional superlattices. ${ }^{17}$

\section{The influence of the conformation of oleic acid on $\gamma-\mathrm{Fe}_{2} \mathrm{O}_{3}$ maghemite nanocrystals}

To investigate the steric influence of the alkyl change on the synthesis and the stabiliztion of the nanocrystals, we investigated the two cis and trans isomers, oleic acid and elaidic acid. Kurikka et al. reported that the carboxylic acid is bonded to the $\gamma-\mathrm{Fe}_{2} \mathrm{O}_{3}$ nanocrystals via ionic bonds. ${ }^{1}$ Based on the observed CO-stretching modes in Fourier transform infrared spectra, it is assumed that carboxylic acids coordinate only with one oxygen to the $\mathrm{Fe}^{3+}$ as opposed to a symmetrical coordination involving both oxygens. ${ }^{7}$ Monodisperse and self-assembly of $12-\mathrm{nm} \gamma-\mathrm{Fe}_{2} \mathrm{O}_{3}$ maghemite nanocrystals were obtained with both acids as shown in both pictures [Figs. 4(a) and 4(b)]. Therefore, our conclusion is that the carboxyl acid head is the main influence on the interaction between surfactant and surface, whereas the structure of carboxyl acid tail does not affect or has only minor influence on
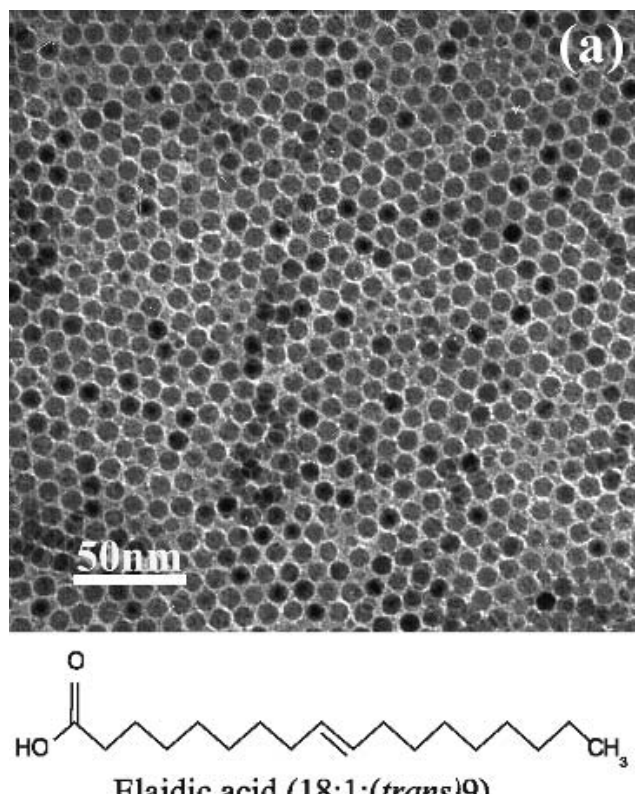

Elaidic acid (18:1;(trans)9)

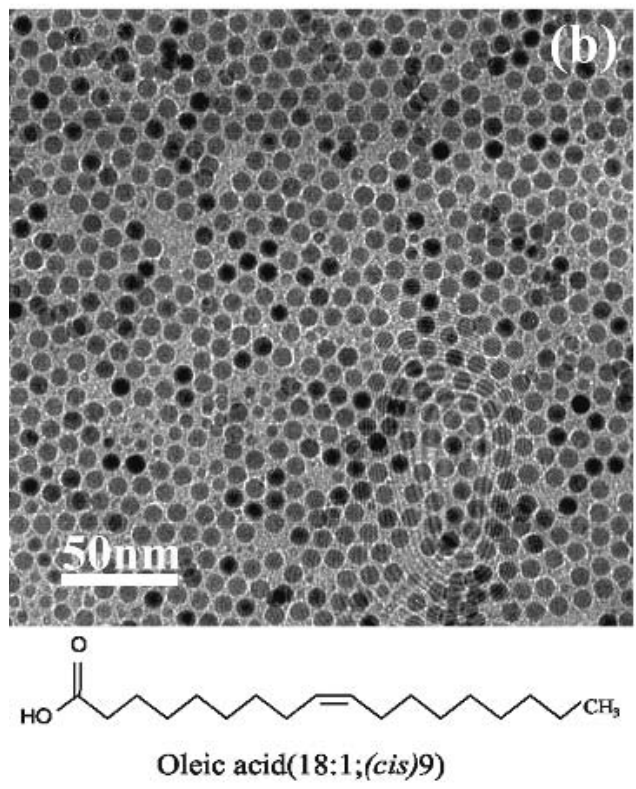

FIG. 4. TEM micrographs of $\gamma-\mathrm{Fe}_{2} \mathrm{O}_{3}$ nanocrystals coated by (a) elaidic acid and (b) oleic acid. 
the evolution of the nanocrystals during synthesis and stabilization of the particles.

\section{The influence of molar ratio of surfactant to iron precursor on $\gamma-\mathrm{Fe}_{2} \mathrm{O}_{3}$ maghemite nanocrystals}

The molar ratio of $1: 3$ between $\mathrm{Fe}(\mathrm{CO})_{5}$ to oleic acid was widely used in iron oxide nanocrystal synthesis because of the high quality of final products. Apparently, much more excessive oleic acid was used in iron oxide nanocrystal synthesis. The excessive dissociated oleic acid molecules in the solution effectively controlled the trend of particle growth. As previously mentioned, oleic acid reacts with the iron pentacarbonyl and facilitates the decomposition reaction. Hyeon and co-workers reported that the particle size decreased when the ratios of $\mathrm{Fe}(\mathrm{CO})_{5}$ to oleic acid increased from 1:3 to $1: 2$ and 1:1, and the particle quality also deteriorated. ${ }^{7}$ However, too much oleic acid will also impede the reaction. Our experiments showed that when the molar ratio of $\mathrm{Fe}(\mathrm{CO})_{5}$ to oleic acid was higher than 1:5, nanocrystals did not form due to hindered nucleation. To optimize reaction conditions, 1:1, 1:2, and 1:3 molar ratio of $\mathrm{Fe}(\mathrm{CO})_{5}$ and oleic acid were tested. We observed the change of decomposition temperature, as shown in Fig. 5(a). When the concentration of oleic acid is low (molar ratio 1:1), the decomposition temperature decreased to $265^{\circ} \mathrm{C}$, and the particle size was about $4 \mathrm{~nm}$ because there was not enough oleic acid to arrest isolated iron atoms and
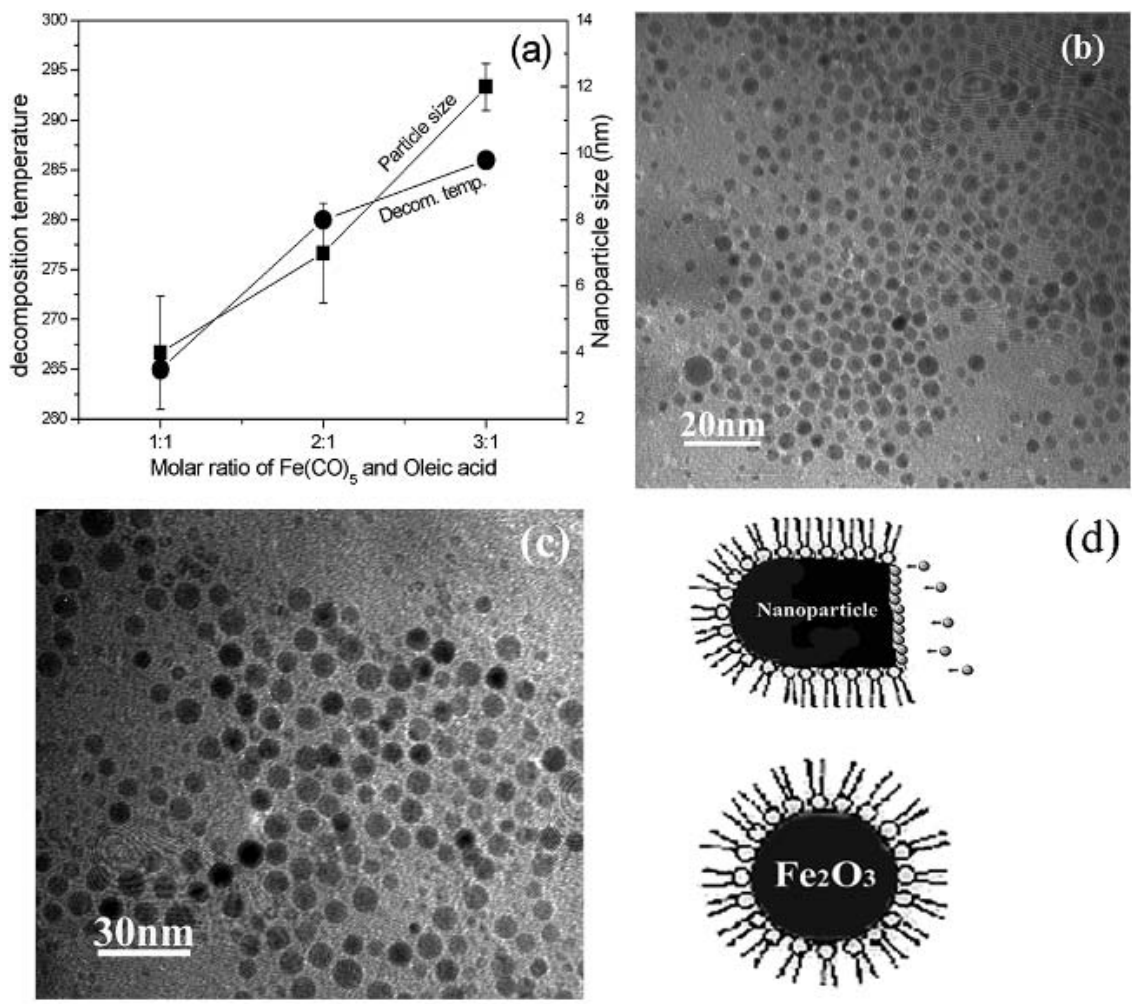

(d)

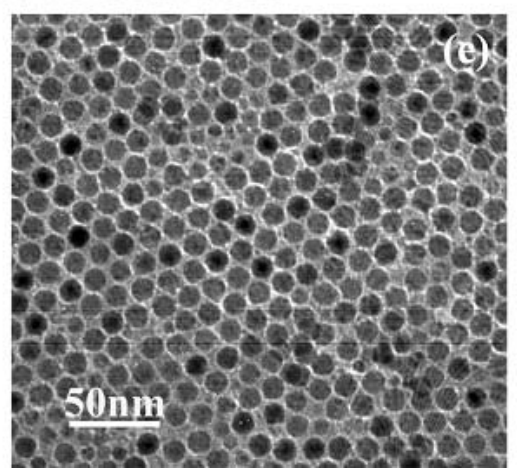

FIG. 5. (a) Decomposition temperature and particle size as molar ratio varies; TEM micrographs of $\mathrm{Fe}_{2} \mathrm{O}_{3}$ nanocrystals when molar ratio of $\mathrm{Fe}(\mathrm{CO})_{5}$ to oleic acid was (b) 1:1 and (c) 1:2. (d) Nanocrystal growth when surfactant was (upper) insufficient and (lower) sufficient. (e) TEM micrographs of $\mathrm{Fe}_{2} \mathrm{O}_{3}$ nanocrystals when molar ratio of $\mathrm{Fe}(\mathrm{CO})_{5}$ to oleic acid was 1:3. 

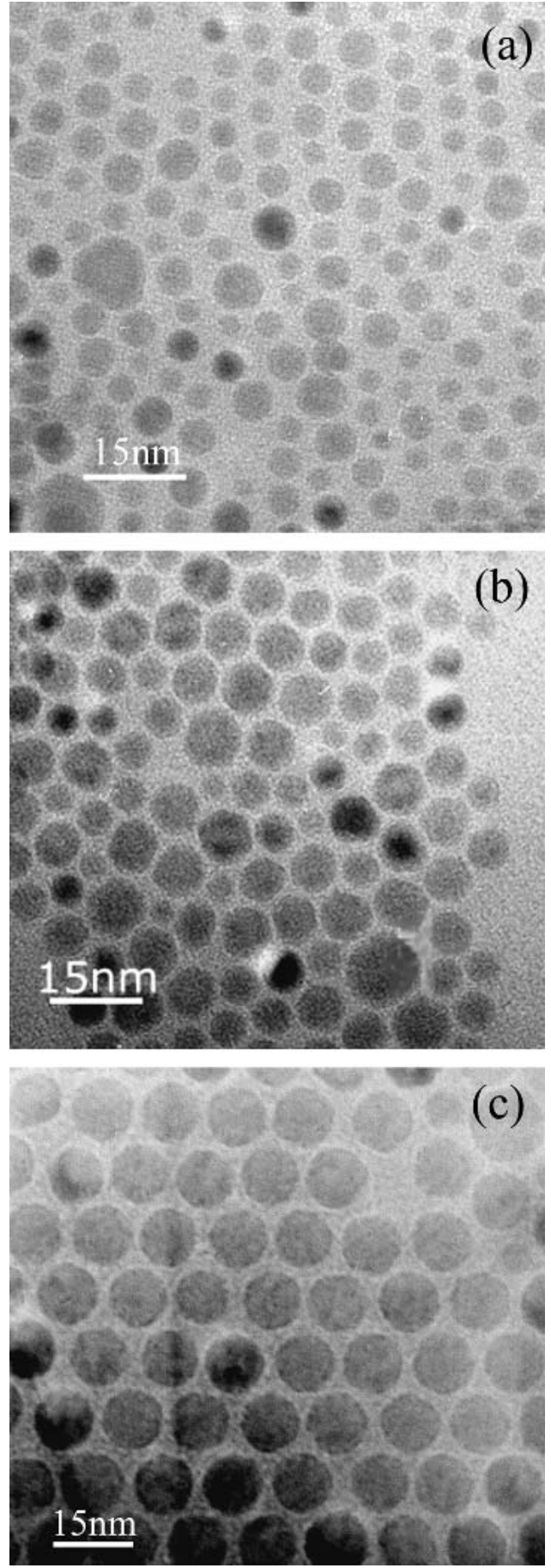

FIG. 6. TEM micrographs of $\mathrm{Fe}_{2} \mathrm{O}_{3}$ nanocrystals made by reheating to $350{ }^{\circ} \mathrm{C}$ for $1 \mathrm{~h}$ when molar ratio was (a) $1: 1$, (b) $1: 2$, and (c) $1: 3$.

nucleation is easy; however, we can also see from Figs. 5(b) and 5(c) that the particle shape is poor because when the nucleus began to grow, the growth of some crystal facets occurred, most likely due to not enough ligand available to passivate the surface and reduce the surface energy [Fig. 5. (d)]. When 1:2 molar ratio was used, the decomposition temperature was $280{ }^{\circ} \mathrm{C}$ and particle size was about $7 \mathrm{~nm}$, which is consistent with Hyeon's result. In this case, particle quality was improved but the size distribution of nanocrystals was too broad to allow selfassembly during evaporation of solvent. When 1:3 molar ratio was adopted, uniform and self-assembled iron oxide particles were produced [Fig. 5(e)]. Compared with Figs. 5(b) and 5(c), particles in Fig. 5(e) were uniform, spherical, and self-assemble into a close-packed structure, which shows the particles adopt positions to minimize surface energy and maximize particle interaction. The decomposition temperature has a major influence on particle size and shape. This is confirmed by the following experiments. Samples shown in Figs. 5(b), 5(c), and 5(e) obtained with molar ratios of 1:1, 1:2, and 1:3 were isolated and heated up again in trioctylamine with surfactant to $350{ }^{\circ} \mathrm{C}$ for $2 \mathrm{~h}$ and characterized again by TEM. Regularity of shape is greatly improved as shown in Figs. 6(a) and 6(b). Although a portion of the particles in Fig. 6(a) are still $4 \mathrm{~nm}$ in size, some of them grew bigger, leading to a broader size distribution. Figure 6(b) shows a similar picture. Most of the particles are spherical and self-assemble into closed-packed distribution. Ostwald ripening leads to the growth of larger particles and to the shrinking of smaller particles. Particles grow into a low surface energy spherical shape. Figure 6(c) shows that 11-nm particles did not increase in size during the heat treatment, as this is presumably an optimized diameter under these conditions.

\section{CONCLUSIONS}

The influence of capping groups on $\gamma-\mathrm{Fe}_{2} \mathrm{O}_{3}$ maghemite nanocrystals has been studied. The results show that carboxylic acid is an effective surfactant in $\gamma-\mathrm{Fe}_{2} \mathrm{O}_{3}$ nanocrystal synthesis. The length of carboxylic acid plays an important role in controlling the particle size and interparticle separation in two-dimensional superlattices. The particle size and inter-superlattice distance were bigger as the length of carboxylic acid increased. The carboxylic acid also "catalyzes" the decomposition reaction leading to decreased decompositon temperatures of iron pentacarbonyl. This effect is strongest for shortchain acids with the higher dipole moment and smallest steric barrier. The conformation of double bond in oleic acid did not show noticeable influence on the reaction. The molar ratio between iron precursor and surfactant was systematically investigated, particles made with insufficient surfactant (less than threefold excess) were generally small, not uniform, and the shape irregular; particles made with sufficient surfactant are uniform, monodispere, and spherical and can easily self-assemble in extended two- and three-dimensional superlattices. 


\section{ACKNOWLEDGMENTS}

We would like to thank Dr. Limin Huang and Dr. Wei $\mathrm{Xu}$ for Chem 3D calculations and discussion. This work was supported primarily by the MRSEC program of the National Science Foundation under Award No. DMR0213574.

\section{REFERENCES}

1. K.V.P.M. Shafi, A. Ulman, X. Yan, N-L. Yang, C. Estoornes, H. White, and M. Rafailovich, Langmuir 17, 5093 (2001).

2. Y. Li and J. Liu, Chem. Mater. 13, 1008 (2001).

3. C.L. Cheung, A. Kurtz, H. Park, and C.M. Lieber, J. Phys. Chem. B 106, 2429 (2002).

4. M.P. Morales, S. Veintemillas-Verdaguer, M.I. Montero, C.J. Serna, A. Roig, L. Casas, B. Martinez, and F. Sandiumenge, Chem. Mater. 11, 3058 (1999).

5. V.F. Puntes, K.M. Krishnan, and P. Alivisatos, Appl. Phys. Lett. 78, 2187 (2001).
6. S. Sun and C.B. Murray, J. Appl. Phys. 85, 4325 (1999).

7. T. Hyeon, S.S. Lee, J. Park, Y. Chung, and H.B. Na, J. Am. Chem. Soc. 123, 12798 (2001).

8. T.W. Smith and D. Wychick, J. Phys. Chem. 84, 1621 (1980).

9. C.L. Cheung, A. Kurtz, H. Park, and C.M. Lieber, J. Phys. Chem. B 106, 2429 (2002).

10. C.B. Murray, S. Sun, W. Gaschler, H. Doyle, T.A. Betley, and C.R. Kagan, IBM J. Res. Dev. 45, 47 (2001).

11. Y-w. Jun, S-M. Lee, N-J. Kang, and J. Chenon, J. Am. Chem. Soc. 123, 5150 (2001).

12. Z. Wu, R.E. Benfield, L. Guo, H. Li, Q. Yang, D. Grandjean, Q. Li, and H. Zhu, J. Phys.: Condens. Matter 13, 5269 (2001).

13. A.J.I. Ward and E.C. O'Sullivan, Langmuir 10, 1985 (1994).

14. L.M. Bronstein, O.A. Platonova, A.N. Yakunin, I.M. Yanovskaya, and P.M. Valetky, Langmuir 14, 252 (1998).

15. B. Jeyadevan, Y. Suzuki, K. Tohji, and I. Matsuoka, Mater. Sci. Eng. A217/218, 54 (1996).

16. C.B. Murray, S. Sun, H. Doyle, and T. Betley, MRS Bull. 26, 985 (2001).

17. M.P. Pileni, ACS Symp. Ser. 679, 29 (1997). 